\title{
Utility of a combined test of anorectal manometry, electromyography, and sensation in determining the mechanism of 'idiopathic' faecal incontinence
}

\author{
W M Sun, T C Donnelly, N W Read
}

\begin{abstract}
Combined tests of anorectal manometry, sphincter electromyography and rectal sensation were carried out in $\mathbf{3 0 2}$ patients with faecal incontinence (235 women, 67 men). The results obtained were compared with 65 normal subjects ( 35 women, 30 men). A mechanism for incontinence was identified in all and the majority of patients had more than one abnormality. Two hundred and seventy eight patients $(92 \%)$ had a weak external anal sphincter, 185 of these $(67 \%$, mostly women) also showed abnormal perineal descent, and 14 women showed clinical evidence of sphincter damage as a result of obstetric trauma. Ten per cent of patients with impaired external anal sphincter contraction showed associated evidence of spinal disease (impaired rectal sensation plus attenuated or enhanced reflex external anal sphincter activity). Unlike the other groups, the 'spinal' group contained equal numbers of men and women. Ninety seven patients (32\%) had evidence of a weak internal anal sphincter. The external sphincter was also very weak and $92 \%$ of these patients also had perineal descent. Eighty two patients (27\%) showed an unstable internal sphincter, characterised by prolonged 'spontaneous' anal relaxation under resting conditions and an abnormal reduction in anal pressure after con-

tion of the external anal sphincter. ${ }^{1-4}$ Increases in intraabdominal pressure, rectal contraction and the rapid entry of larger volumes into the rectum threaten continence and are countered by a compensatory contraction of the external anal sphincter. ${ }^{15}$ The external sphincter responses depend on adequate afferent mechanisms, properly functioning integrative circuitry in the spinal cord and sufficiently strong muscular contraction. The external sphincter response to rectal distension is critically linked to conscious rectal sensations $s^{5}$ and must therefore involve cortical modulation. It follows therefore that faecal incontinence could arise from a variety of possible defects; external sphincter weakness, internal sphincter weakness, impaired rectal sensation, neurological lesions in the spinal cord or brain, and increased rectal contractility. Logically, these different mechanisms would require different treatments.

Over a period of three years, we used a combined test of the manometric, electrophysiological and sensory responses of the rectum and anal sphincters to rectal distension, increases in intraabdominal pressure and conscious contraction of the sphincter to identify the mechanism of faecal incontinence in 302 patients referred to our unit. This paper reports our results and evaluates the usefulness of the technique.
\end{abstract} scious contraction of the sphincter or an increase in intraabdominal pressure. One hundred and forty two patients $(\mathbf{4 7 \%})$ had a hypersensitive rectum associated with enhanced anorectal responses to rectal distension. All these patients had an abnormally weak external sphincter, suggesting that the hypersensitive or 'irritable' rectum should not be regarded as a cause of faecal incontinence unless accompanied by external sphincter weakness. Twenty four patients (8\%) showed a normal basal and squeeze pressures and impaired rectal sensation; six showed giant rectal contractions during rectal distension. The results show that idiopathic faecal incontinence is not caused by a single abnormality, and it is suggested that combined anorectal manometry, electromyography, and sensory testing is a useful technique to identify the causes of faecal incontinence and provide a basis for appropriate treatment.

The mechanism for maintaining faecal continence is complicated. Under resting conditions and during slow entry of contents into the rectum, continence is maintained by the tonic contraction of the internal anal sphincter supplemented to a lesser or greater degree by contrac-

\section{Methods}

\section{SUBJECTS}

The study group consisted of 302 patients referred to our unit for investigation of faecal incontinence over a period of three years. Sixty seven were men (aged 15-82, median 52 years) and 235 were female patients (aged 18-87, median 53 years; $p>0.05$ ). Eighty per cent of female patients had vaginal deliveries. Of those, $41 \%$ had had three or more children. All patients had at least one episode of incontinence a month, and their problem had been present for at least three months.

Patients with a history and clinical signs suggesting spinal injury or disease, non-obstetric trauma to the perineum, diabetes mellitus, generalised neuropathy, and dementia were excluded from the study.

The results obtained from patients were compared with 65 normal subjects, 30 men (aged 2063, median 45 years) and 35 women (aged 21-55, median 48 years; $p>0.05$ ), who were recruited from a population of university students and staff. Seventy seven per cent of female volunteers had vaginal deliveries. None of the normal
Gastrointestinal Motility 
subjects suffered from any disturbance of defecation or were taking any medication likely to influence anorectal function.

\section{ETHICAL CONSIDERATIONS}

All patients and volunteers gave their written informed consent for the study to be carried out. The protocol was approved by the Ethical Subcommittee of the Sheffield Area Health Authority.

The methods and the protocol used in this study have been described previously. ${ }^{6}$ In the technique used in our laboratory, pressures at multiple sites in the rectum and anal canal $(0.5$, $1 \cdot 0,1 \cdot 5,2 \cdot 0,2 \cdot 5$ and $4 \cdot 5 \mathrm{~cm}$ from the anal verge) were measured with a narrow polyvinyl seven lumen tube ( $4 \mathrm{~mm}$ od) equipped with perfused side ports. The side holes were perfused with water at a rate of $0.2 \mathrm{ml}$ per minute by a low compliance pressurised perfusion system (Mui, PIP 2, Mississauga, Ontario, Canada), and pressure were measured by means of pressure transducers (Statham 23ID, Oxnard, California, USA), which were situated in each perfusion line and connected through amplifiers to a multichannel chart recorder (Hewlett Packard, 7758A, Waltham, Mass, USA). A highly compliant thin walled balloon constructed from an unstretched condom (Durex Dry; LRC Production Ltd, London, UK) was tied at the tip of the probe to distend the rectum. The proximal pole of this balloon was $8 \mathrm{~cm}$ from the anal verge.

The electrical activity of the sphincter was recorded using a bipolar wire electrode, consisting of two trimel coated wires (diameter 0.025 $\mathrm{mm}$ ) with their ends bared, hooked and offset to avoid electrical contact. ${ }^{7}$ The wires were inserted into the superficial external anal sphincter or into the intersphincteric groove between the external anal sphincter and internal anal sphincter inside a 23G hypodermic needle, which was subsequently withdrawn, leaving the hooked ends of the wires in situ. The free ends of the wires were bared and attached to an amplifier (Differential type 21C01 URO-DISA, Copenhagen, Denmark; frequency range: $1 \mathrm{~Hz}-10 \mathrm{kHz}(-3 \mathrm{~dB}))$, which was connected through an integrator (AC to RMS convertor: Analog Devices AD536, East Molesey, Surrey, UK) to the chart recorder. Both raw and integrated records $(170 \mathrm{~ms}$ time constant) were displayed on the chart recorder.

Anorectal motility was recorded under resting between groups. IAS =internal anal sphincter; $E A S=$ external anal sphincter.

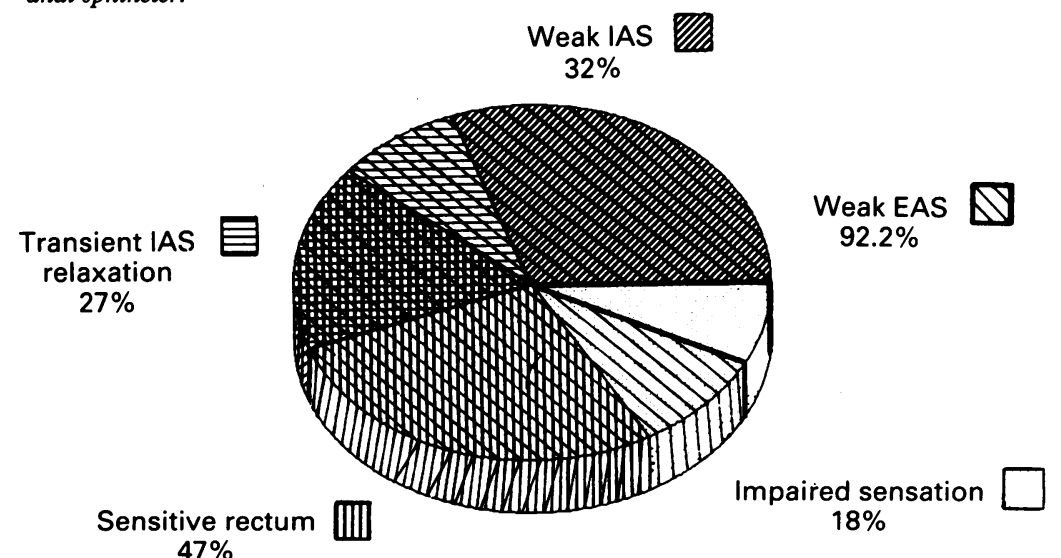

conditions for at least 20 minutes. After the resting period, the subject was instructed to contract his anal sphincter as hard as he could for a period of one minute. This was repeated two more times with gaps of at least a minute between the contractions. Then the rectal balloon was serially inflated with $10,20,40,60$, and $100 \mathrm{ml}$ of air. Each inflation was maintained for one minute and a gap of at least one minute was allowed before the next inflation. The subject was asked to report his subjective sensations during each inflation and to indicate the duration of the sensation on the chart using a remote event marker. The lowest distending volumes at which the balloon was perceived, and sensations of gas in the rectum (wind), a desire to defecate and pain were experienced, were noted on the chart, and the preinflation, postinflation and residual presures during inflation in each channel were noted. After a further rest period of at least 10 minutes, the subject was instructed to increases in intraabdominal pressure by blowing up a balloon (Sainsbury's Partytime Round Balloons, 747/350, J Sainsbury plc, London). This manoeuvre was repeated twice and a gap of at least one minute was allowed in between.

\section{STATISTICAL ANALYSIS}

The statistical significance of the differences in the pressures were assessed using analysis of variance followed by Sheffés method for multiple comparison. ${ }^{8}$ The sensory data were analysed by using Mann-Whitney U-test. $\chi^{2}$ test was used to determine the differences between the percentages of subjects in each group who showed a certain phenomenon.

\section{Results}

Combined anorectal function tests revealed abnormalities in a total of 302 patients who presented with faecal incontinence. The majority of patients had more than one abnormality (Fig l).

\section{WEAKNESS OF EXTERNAL ANAL SPHINCTER}

Two hundred and seventy eight of the 302 patients $(92 \cdot 2 \%)$ [58/67 male (87\%), 220/235 female $(94 \%)$ ] had squeeze pressures that were below the normal range for our laboratory (mean two SD; male: 172-340; female: 90-240 $\left.\mathrm{cmH}_{2} \mathrm{O}\right)$. External sphincter responses to rectal distension and increases in intraabdominal pressure were also impaired. The sphincter pressure was lower than the steady state rectal pressure in 194 of these patients $(70 \%)$ during rectal distension and $230(84 \%)$ leaked during this manoeuvre. One hundred and eighty six of these patients $(67 \%)$ also leaked during increases in intraabdominal pressure, and the anal pressure was lower than the rectal pressure in all except two of these, but in none of the patients who were dry during this manoeuvre. None of the normal subjects leaked perfusion fluid or showed an adverse rectoanal pressure gradient during either of these manoeuvres.

The patients with weak external sphincter could be segregated into several different categories (Fig 2). 


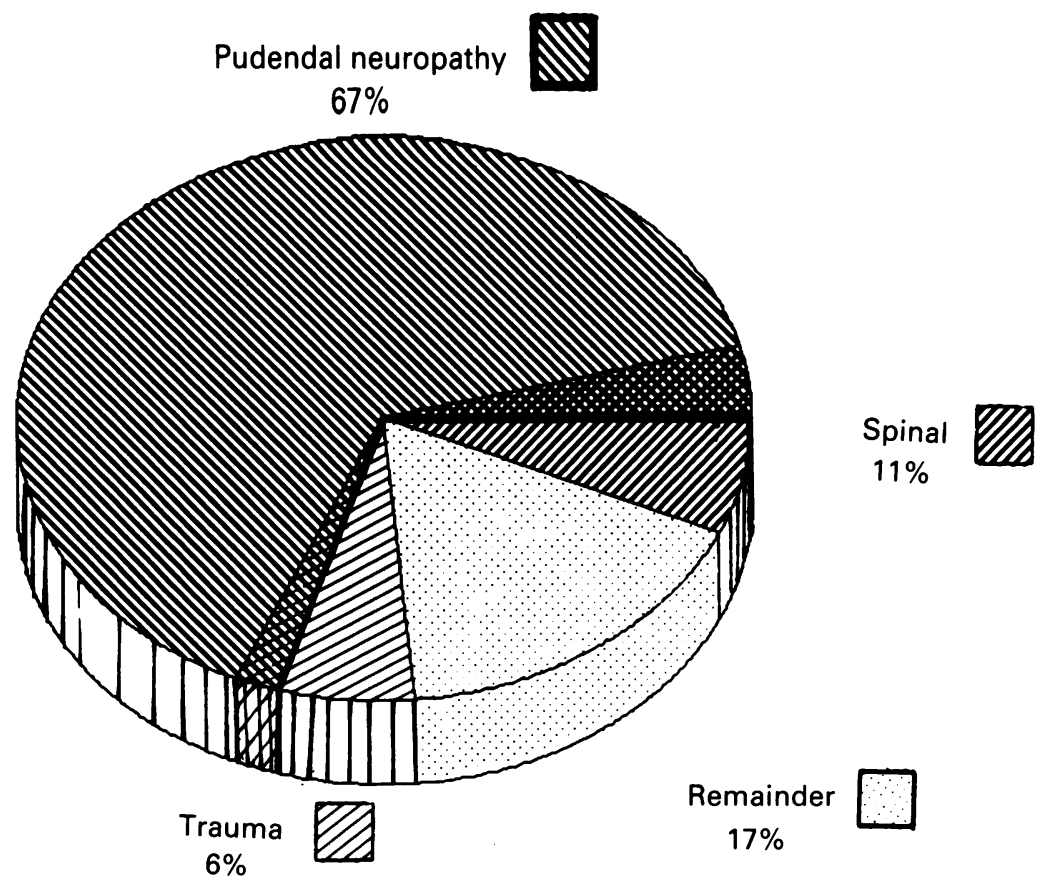

Figure 2: Distribution of putative causes of a weak external sphincter in 278 patients with faecal incontinence $(\%)$. Note the overlapping between groups.

\section{Weak external anal sphincter with perineal descent}

Sixty seven per cent of patients with weak external anal sphincters [31/58 (53\%) male, $154 / 220(70 \%)$ female] $(61 \cdot 3 \%$ of the total showed abnormal perineal descent in that the position of their pelvic floor assessed by radiography or perineometry ${ }^{90}$ descended more than $2 \mathrm{~cm}$ when they strained. Female patients accounted for $83 \%$ of this group and $80 \%$ of these women had multiple vaginal deliveries ( $>$ two children). No patient with abnormal perineal descent had sphincter pressures that were within the normal range. All patients exhibited electrical activities of the external anal sphincter during squeezing, straining, and increases in intraabdominal pressure, but the mechanical effort was weak.

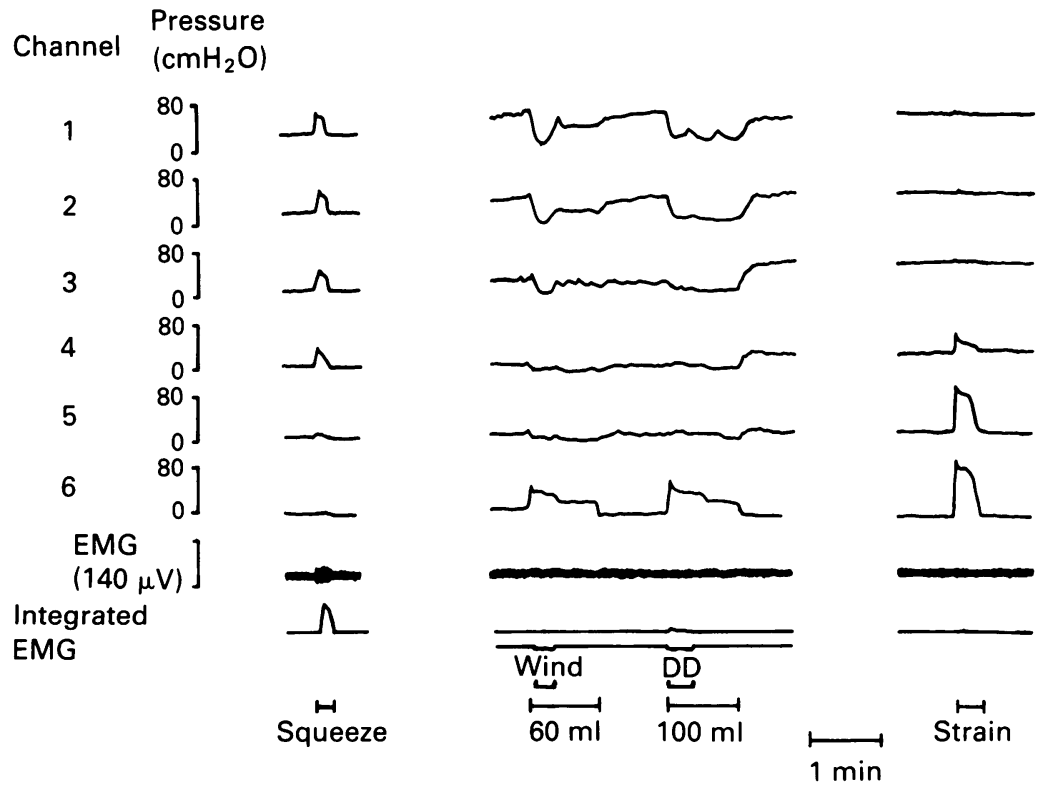

Figure 3: Multiport recordings of anal pressure and the electrical activity of the external anal sphincter during maximum conscious contraction of the (EAS) (left panel), during rectal distension (middle panel), and during straining (right panel) in a typical patient with a suspected low spinal or cauda equina lesion. Channels $1-6$ represent ports $0 \cdot 5,1 \cdot 0,1 \cdot 5,2 \cdot 0$, $2 \cdot 5$, and $4.5 \mathrm{~cm}$ from the anal verge. Note that there is appropriate conscious contraction of the sphincter but no increase in electrical or mechanical activity of the external anal sphincter generated by rectal distension or an increase in intraabdominal pressure.

Forty eight per cent of patients (89) with weak external sphincters and perineal descent also had abnormally weak internal anal sphincters, $50 \%$ had a hypersensitive rectum (see below) and $6.5 \%$ also had evidence of sphincter trauma.

Thirty per cent of the patients with weak external anal sphincter and perineal descent (55) also had clinical evidence of either rectal prolapse or anterior mucosal prolapse or solitary rectal ulcer.

\section{Weak external anal sphincter with history of trauma}

Fourteen female patients with weak external sphincters (6\% of total female patients) had a previously undetected defect in their external sphincter ring on examination and/or during electromyography and a history of perineal tear during childbirth. Electrical activity of the divided external anal sphincter appeared normal in all except two patients (17\%). During conscious contraction, two patients showed a reduction in sphincter pressure instead of the normal increase. The average period of time from their first childbirth to their first consultation for faecal incontinence was 14 years (range two to 40 years). These patients all reported that although they were aware of the threat of incontinence, they were unable to stop it taking place. Seven patients underwent a sphincter repair and a satisfactory result was achieved in five of them. The two patients who did not improve had impaired electrical activity of the external anal sphincter.

\section{Weak and absent conscious external anal} sphincter contraction with blunted rectal sensation and abnormal reflex activity (occult spinal lesions). Thirty one patients (16 men, 15 women; $10 \%$ of the total) with impaired conscious contraction of the external sphincter also had blunted rectal sensation (threshold for sensation $\geqslant 40 \mathrm{ml}$, threshold for desire to defecate $\geqslant 100 \mathrm{ml}$ ), thus fulfilling the minimal criteria for patients with spinal lesions."

Twenty four of these patients (13 men, 11 women) had absent external sphincter electrical and mechanical responses to rectal distension and increases in intraabdominal pressure (Fig 3) and exhibited leakage of infusion fluid during those manoeuvres. Eight (33\%) had no conscious contraction of the external sphincter. Residual pressures during rectal distension were the lowest of any group and equalled the rectal pressure. These patients fulfilled our criteria for low spinal or cauda equina lesions.

In the remaining seven patients (three men, four women $)(2 \cdot 4 \%$ of the total) sphincter activity was markedly enhanced when they moved their legs or coughed, and during rectal distension or increase in intraabdominal pressure caused by inflating a party balloon (Fig 4). This kept the anal pressures above rectal pressures and the leakage was rare. None of these patients could contract their external sphincter consciously. These findings suggested the existence of lesions above the conus medullaris. 
Channel $\begin{aligned} & \text { Pressure } \\ & \left(\mathrm{cmH}_{2} \mathrm{O}\right)\end{aligned}$

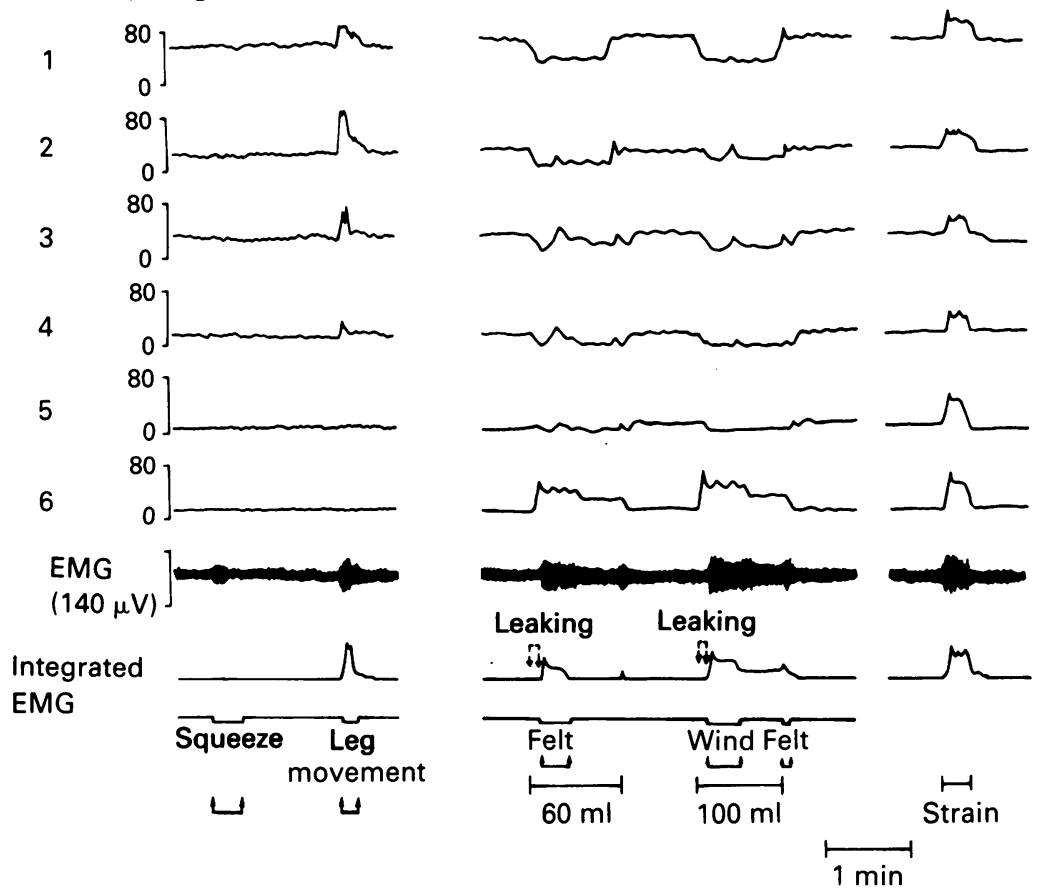

Figure 4: Recordings of anorectal pressure at ports situated $0 \cdot 5,1 \cdot 0,1 \cdot 5,2 \cdot 0,2 \cdot 5$, and $4 \cdot 5$ $\mathrm{cm}$ from the anal margin (channels 1-6) and the electrical activity of the external anal sphincter in a patient with a high spinal lesion during rectal balloon distension with 60 and $100 \mathrm{ml}$ of air. There is no conscious contraction of the sphincter (left panel) but reflex response to rectal distension (middle panel), increase in intraabdominal pressure (right panel) and movement of the legs are much increased. Both sensation and external anal sphincter activity are delayed during rectal distension and leakage occurs during that period.

\section{IMPAIRED INTERNAL ANAL SPHINCTER FUNCTION}

\section{Weakness of internal anal sphincter}

Ninety seven patients (32\% of total) showed abnormally low basal pressures and no internal anal sphincter relaxation when the rectum was distended $^{12}$ (Fig 5). All patients in this group also had abnormally low squeeze pressures and attenuated external anal sphincter responses to increases in intraabdominal pressure, suggesting a weak external anal sphincter. Ninety two per cent of these patients had abnormal perineal descent. Rectal sensation was normal in all subjects.

\section{Transient internal anal sphincter relaxation}

Abnormally frequent spontaneous relaxation of the internal anal sphincter $(>1 / 10 \mathrm{~min}$.) was seen under basal conditions in 82 patients $(27 \%$ of the total) (Fig 6). The relaxation was only associated with compensatory increases in external anal sphincter activity in $23 \%$ of those subjects, and the anal pressure fell to lower values in patients compared with normal subjects (20 (1) v 43 (3) $\left.\mathrm{cmH}_{2} \mathrm{O}, \mathrm{p}<0 \cdot 05\right)$. The external sphincter function was also impaired in this group of patients. Sixty eight per cent of these patients fulfilled criteria for a hypersensitive rectum (see below).

\section{IMPAIRED RECTAL SENSATION}

Fifty five patients (18\% of the total) showed blunted or delayed rectal sensations during rectal balloon distension. Thirty one patients $(56 \%)$ had impaired or absent conscious contraction of the external anal sphincter, and abnormal external anal sphincter reflexes and were suspected of having occult spinal lesions and included in category 3 . The remaining 24 patients in this group (44\%) had basal and squeeze pressures were within normal range.

There were two abnormalities, which often occurred in combination. In 40 patients, the rectal volume that induced internal anal sphincter relaxation was lower than that which induced rectal sensation and an increase in external anal sphincter activity. Patients in this group did not perceive any rectal sensation until $60 \mathrm{ml}$ of air had been introduced (normal range 10-20 ml). Thirty eight patients showed abnormally delayed sensation. Thus although these patients could perceive distension with some volumes, they failed to contract the external anal sphincter in time to compensate for a relaxation of the internal anal sphincter. Perfusion fluid often leaked at this time but was arrested as soon as the patients perceived sensation and the external anal sphincter activity increased (Fig 7).

\section{Impaired rectal sensation associated with giant rectal} waves

Six patients with impaired rectal sensation and normal anal pressures ( $2 \%$ of total) showed abnormally large rectal pressure waves $(\geqslant 20$ $\mathrm{cmH}_{2} \mathrm{O}$, lasting $\geqslant$ five seconds) during rectal

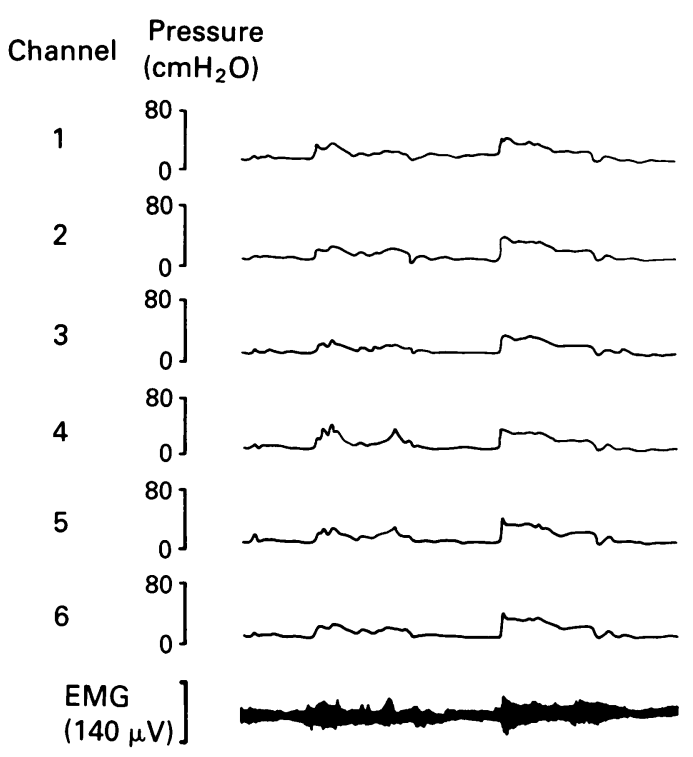

Integrated EMG

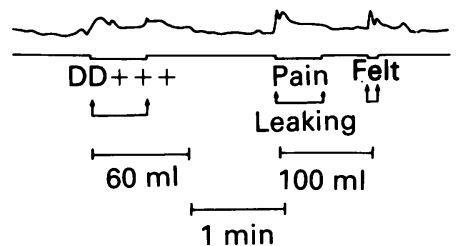

Figure 5: Recordings of anorectal pressure and the electrical activity of the sphincter in a female patient with impaired internal anal sphincter function before, during, and after inflation of a rectal balloon with 60 and $100 \mathrm{ml}$ of air. Channels $1-6$ represent ports situated $0 \cdot 5,1 \cdot 0,1 \cdot 5,2 \cdot 0,2 \cdot 5$ and $4.5 \mathrm{~cm}$ from the anal margin. Note the abnormally low basal anal pressures, and the absence of anal relaxation during rectal distension. This increase in anal pressure during rectal distension is associated with an increase in the electrical activity of the external anal sphincter. No rebound pressures were observed upon deflating the rectal balloon. The bars (-) indicate when the subject experienced rectal sensation. $D D=$ desire to defecate; +++ indicates the severity of the sensation. 


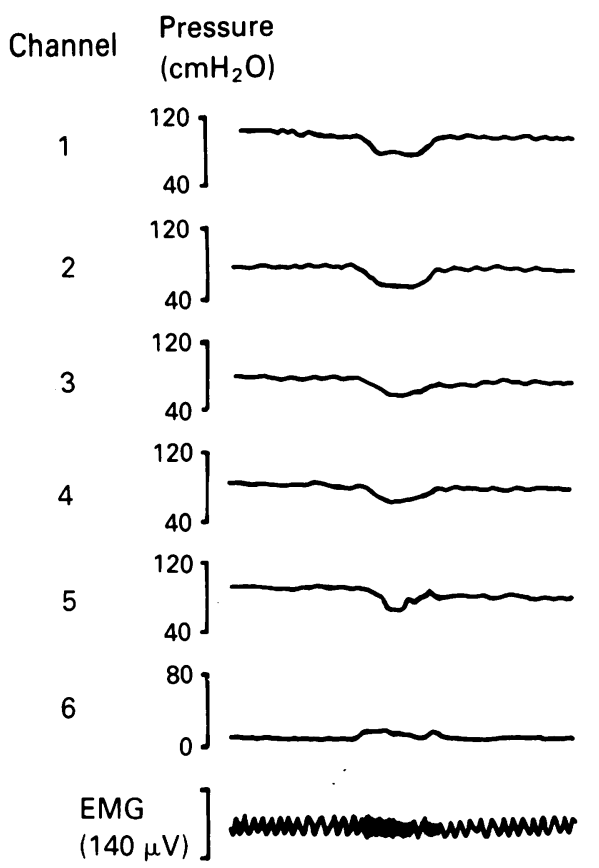

Pressure

$\left(\mathrm{cmH}_{2} \mathrm{O}\right)$
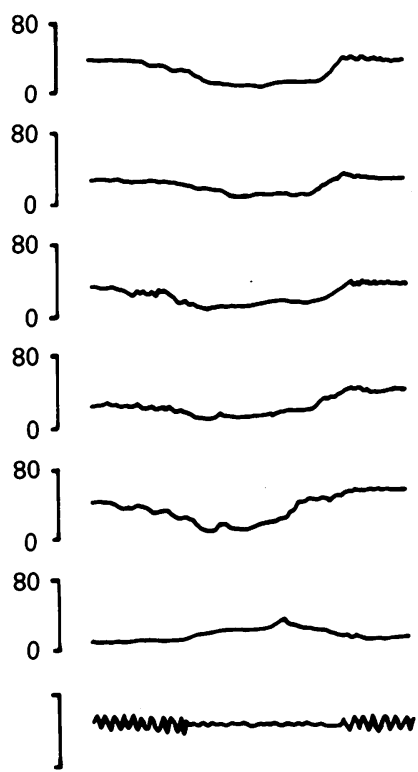

Integrated EMG
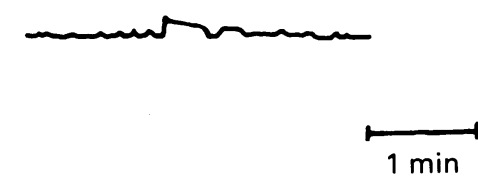

Figure 6: Multiport recordings of anal pressure and the electrical activity of the external anal sphincter and internal anal sphincter during and after an episode of spontaneous anal relaxation in a normal subject (left) and an incontinent patient (right). Channels $1-6$ represent ports situated $0 \cdot 5,1 \cdot 0,1 \cdot 5,2 \cdot 0,2 \cdot 5$ and $4.5 \mathrm{~cm}$ from the anal verge. The relaxation lasted longer in the patient, was accompanied by a oscillation associated with internal anal sphincter activity, but no compensatory increases in external anal sphincter activity.

distension. The large rectal waves were always associated with a relaxation of the internal anal sphincter, and the electrical activities of the external anal sphincter were lower than normal at each volume except $10 \mathrm{ml}$ - for example, 0.04 $(0.002) v 0.06(0.006) \mathrm{mV} / \mathrm{seconds}$ at $100 \mathrm{ml}$ $\mathrm{p}<0.05$. Hence the anal pressures generated were lower than the rectal pressures and leakage occurred.

\section{HYPERSENSITIVE RECTUM}

Forty seven per cent of patients with faecal incontinence showed abnormally low threshold volumes to induce a desire to defecate (normal range; men: $60-150$; women: $50-100 \mathrm{ml}$ ) or pain (normal range; men: $150->200$; women: 100-200 ml). Anorectal manometry revealed that the duration of the internal anal sphincter relaxation was longer than in normal subjects at each distension volume - for example, $>12$ seconds at $10 \mathrm{ml}$, and sustained relaxation of the internal anal sphincter was induced at abnormally low rectal volumes ( $\leqslant 60 \mathrm{ml}$ ) (Fig 8 ) compared with normal volunteers or the rest of the incontinent group. This group of patients showed abnormally reduced rectal compliance $\left(4.7(0.3)\right.$ v $6.9(0.3) \mathrm{ml} / \mathrm{cmH}_{2} \mathrm{O}$ at $100 \mathrm{ml}$; $\mathrm{p}<0.05)$ and exhibited repetitive rectal contractions at abnormally low $(\leqslant 40 \mathrm{ml})$ rectal volumes.

All the patients in this group also had abnormally weak external sphincters and $92(65 \%)$ had an abnormal degree of perineal descent. Fifty five patients (39\%) had abnormally frequent trans- ient internal anal sphincter relaxation and 55 patients had prolapse (36\%), anterior mucosal prolapse $(44 \%)$, or solitary rectal ulcer $(20 \%)$.

\section{Discussion}

The recording of manometric, electrophysiological, and sensory responses to conscious sphincter contraction, rectal distension and increases in intraabdominal pressure revealed several abnormalities that could account for faecal incontinence. Most patients had more than one abnormality.

The majority of patients (92\%) had weakness of the external anal sphincter. Nearly all were

\section{Pressure$$
\begin{aligned}
& \text { Pressure } \\
& \left(\mathrm{cmH}_{2} \mathrm{O}\right)
\end{aligned}
$$

1

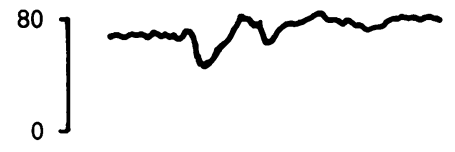

2

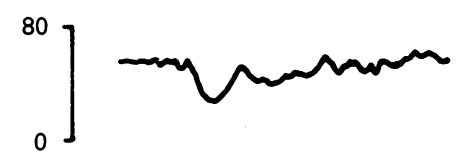

3
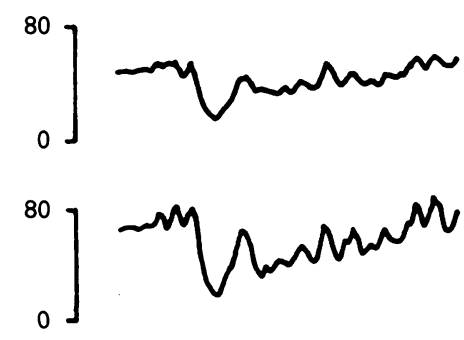

5

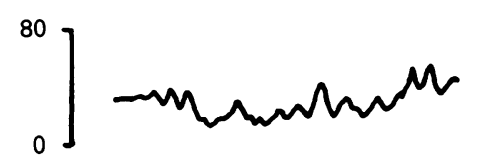

6

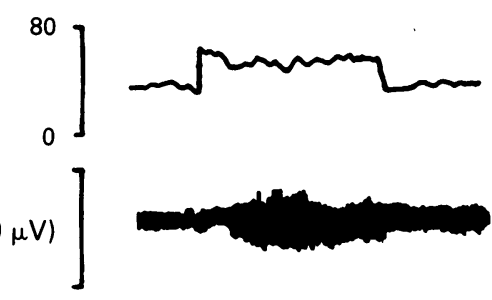

Integrated EMG
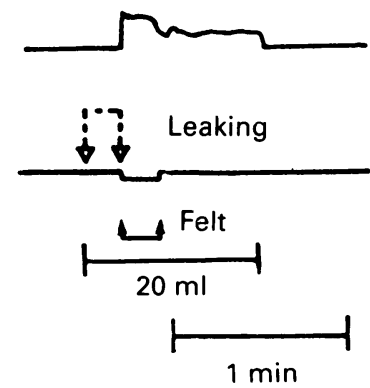

Figure 7: Recordings of anorectal pressure and the electrical activity of the sphincter complex in a patient with delayed rectal sensation during rectal balloon distension with $60 \mathrm{ml}$ of air. Note that the sphincter (IAS) relaxes upon rectal distension, but rectal sensation and the external anal sphincter response are delayed. Leakage occurs during relaxation but is arrested as soon as the suhject perceives rectal sensation and increases the activity in the external sphincter. 


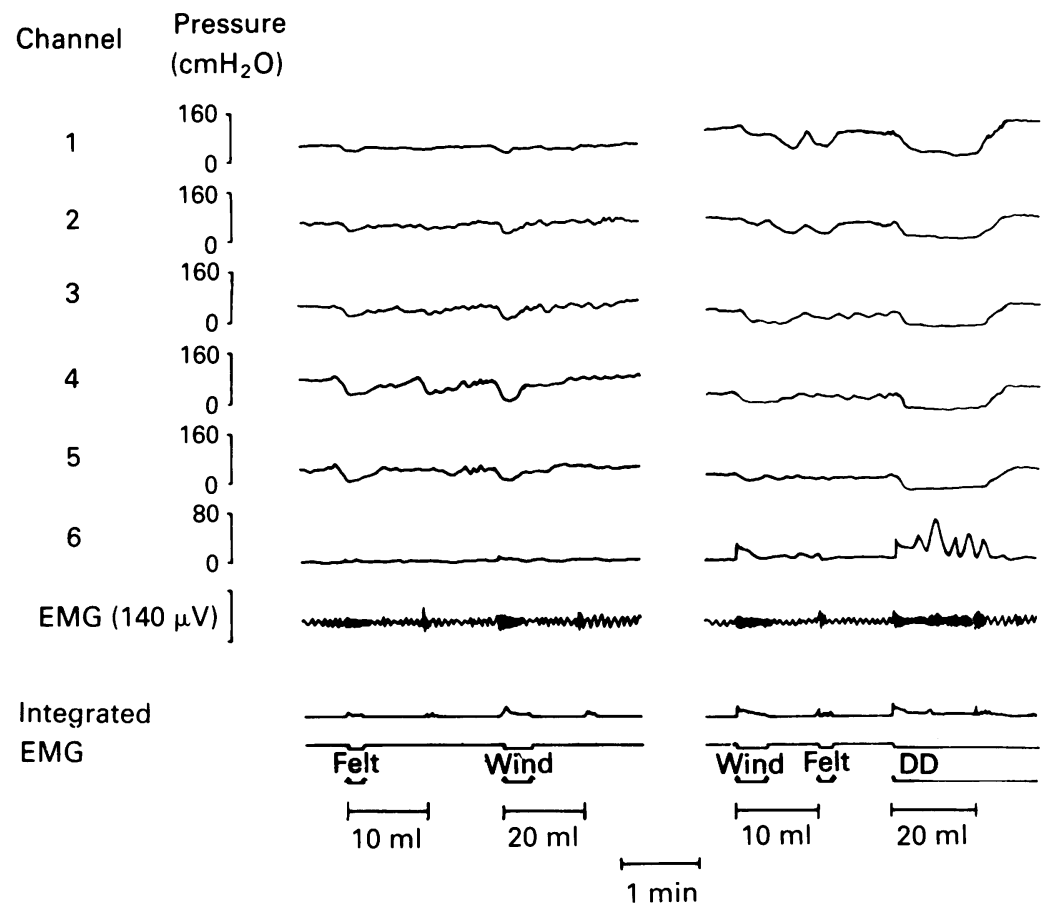

Figure 8: Anorectal recordings in a normal subject ( $a$ ) and an incontinent patient with a hypersensitive rectum $(b)$ during balloon distension. Note (I) lower volumes required to induce desire to defecate in the patient compared with a normal subject; (2) the repetitive rectal contractions in the rectal channels during the balloon distension; (3) profound and prolonged anal relaxation in patient compared with a normal subject during rectal balloon distension. women and most had abnormal descent of the perineum and had undergone multiple vaginal deliveries. Thus our data support the hypothesis that pudendal neuropathy, caused by a traction on the pudendal nerve as it winds around the ischial spine is the most common cause of idiopathic faecal incontinence. ${ }^{1314}$ This mechanism only accounted for incontinence in $58 \%$ of our patients, however. Twelve patients had previously unrecognised trauma to the external sphincter caused by obstetric tears. The defect is usually caused by inadequate suture of the torn sphincter resulting in divided sphincter. The manometric features of a mechanically weak sphincter with normal electromyographic responses cannot be distinguished from pudendal neuropathy. The diagnosis relies upon a careful obstetric history and physical examination. A palpable gap in the sphincter and anal pressure reduction during squeezing support the diagnosis. Mapping out the site of the defect by recording external anal sphincter activity around the circumference of the sphincter can also facilitate diagnosis and guide the surgeon. ${ }^{\text {is }}$ When there is no other condition damaging the external sphincter, direct repair of the defect has a good prognosis. The two patients who were still incontinent after sphincter repair had attenuated electrical activity of the external anal sphincter.

Occult spinal disease is an important cause of incontinence associated with weakness of the external anal sphincter. By studying patients with well diagnosed spinal lesions, ${ }^{\text {" }}$ we have concluded that the combination of impaired or absent conscious contraction of the external anal sphincter with blunted rectal sensitivity strongly suggests a spinal lesion. " The identification of low spinal/cauda equina lesions as opposed to high spinal lesions then depends on whether external anal sphincter responses to rectal distension or increases in intraabdominal pressure are absent or enhanced. Physiological tests of this sort may be the only means of identifying spinal disease affecting the sphincters. ${ }^{16}$ None of the patients gave any history of spinal injury and clinical neurological examination revealed no evidence of cerebrospinal disease. These patients are important to recognise for two reasons. First, anorectal features may be an early feature of progressive neurological disease, and second, these patients are unlikely to respond to anorectal surgery but may benefit from biofeedback training.

Equal numbers of male and female patients fulfilled the criteria for occult spinal lesions. This was in contrast with the other groups in which there was a marked female predominance. Thus occult spinal lesions were the cause of incontinence in one in four male patients but only one in 20 female patients.

Most studies of faecal incontinence have emphasised the role of the puborectalis and external anal sphincter. ${ }^{17-21}$ in contrast, the role of the internal anal sphincter has been largely ignored until very recently. Our results showed that $32 \%$ of patients had evidence of severe weakness of the internal anal sphincter; abnormally low resting pressure and no relaxation during rectal distension. All of these patients, however, also had abnormal external anal sphincter weakness, the vast majority $(92 \%)$ associated with abnormal pelvic floor descent, the rest with obstetric trauma. Patients with combined external anal sphincter and internal anal sphincter weakness are more severely incontinent than patients who have external anal sphincter weakness alone. ${ }^{12}$ The association of internal anal sphincter weakness with perineal descent has been noted previously. ${ }^{12}$ Several hypotheses have been proposed: (1) the extremely weak striated muscle exposes the internal anal sphincter to traction of the tissue of the pelvic floor, (2) the abnormal descent of the pelvic floor may damage the delicate sympathetic nerves, which are thought to enhance the tone of the internal anal sphincter, ${ }^{22-24}$ (3) perineal descent may damage excitatory nerves to the internal anal sphincter contained within the pudendal nerve. ${ }^{25}$

A surprising $47 \%$ of patients had an abnormally hypersensitive rectum. This has been described in patients with irritable bowel syndrome. ${ }^{26-28}$ These patients also showed the enhanced anorectal reactivity common in irritable bowel syndrome. ${ }^{26}$ Anorectal hyperreactivity does not usually cause incontinence if the sphincter mechanism is normal, but if the external sphincter is weak and/or fails to respond to rectal distension, then the rectal pressure peaks may exceed the sphincter pressure and incontinence may ensue. The combination of an 'irritable anorectum' and a weak external anal sphincter makes these patients particularly difficult to treat. This combination is also characteristic of patients with rectal prolapse and solitary rectal ulcer syndrome, ${ }^{29}$ who comprised $37 \%$ patients in this group.

Over a third of patients with the hypersensitive rectum and incontinence showed an unstable internal anal sphincter, that relaxed spontaneously under basal conditions. ${ }^{30}$ Perhaps the exquisite rectal sensitivity in these patients caused the internal anal sphincter to relax to the slightest provocation. Normal subjects also have spontaneous relaxations but the abnormal fre- 
quency and duration in the patient group and the inability of the impaired external anal sphincter to compensate for a relaxation of the internal anal sphincter means that these episodes can often be associated with incontinence.

All the incontinent patients who had normal sphincter pressures had impaired rectal sensitivity. ${ }^{5}$ Prompt and sensitive perception of rectal distension is tightly linked to contraction of the external anal sphincter. Thus patients with impaired rectal sensation are incontinent because they fail to contract the external anal sphincter to compensate for a relaxation of the internal anal sphincter, induced by rectal distension or contraction. ${ }^{5}$ Leakage of perfusion fluid is common in patients with impaired rectal sensitivity, but ceases as soon as the patient perceives the distension or leakage and contracts the external anal sphincter.

Six patients with impaired rectal sensitivity showed giant contractions in the rectum. This is a feature we had previously seen in diabetic patients with enteric neuropathy and may indicate damage to the autonomic and enteric neurones supplying the distal colon.

In conclusion our results showed that idiopathic faecal incontinence is not just caused by one condition. Not all incontinent patients have evidence of pudendal neuropathy or marked external sphincter weakness. There are a number of different causes, which may occur singly or in combination and these may be distinguished by anorectal function testing.

The identification of pathophysiological subsets is only important if it allows the surgeon or physician to select an appropriate treatment. For example, surgical treatment may be indicated for obstetric trauma and pudendal neuropathy but not for impaired rectal sensitivity, which may be best managed by behavioural modification. Patients with incontinence who have a hypersensitive and hyperreactive rectum might be best managed by drugs before contemplating any surgical procedure to strengthen the sphincter. Other abnormalities, such as transient sphincter relaxation and giant rectal contractions, may have to await the development of new and specific treatments. The challenge now is to conduct anorectal function testing in combination with specific trials of therapy.

1 Sun WM, Read NW, Prior A, Daly J, Cheah SK, Grundy D. The sensory and motor responses to rectal distension vary according to rate and pattern of balloon distension. Gastroenterology 1990; 99: 1008-15.

2 Bennett $\mathrm{R}$, Duthie $\mathrm{H}$. The functional importance of the internal anal sphincter. BrF Surg 1964; 51: 355-7.
3 Frenckner B, Ihre T. Influence of pudendal block on the function of the anal sphincter. Gut 1975; 16: 482-9.

4 Lestar R, Penninckx F, Kerremans R. The composition of anal basal pressure - an in vivo and in vitro study in man. Int $\mathcal{F}$ Colorectal Dis 1989; 4: 118-22.

5 Sun WM, Read NW, Miner PB. The relationship between rectal sensation and anal function in normal subjects and patients with faecal incontinence. Gut 1990; 31: 1056-61.

6 san WM, Read NW. Anorectal function in normal human subjects: effect of gender. Int $\mathcal{f}$ Colorect Dis 1989; 4: 188-96.

7 Basmajian JV, Stecko G. A new bipolar electrode for electromyography. F Appl Physiol 1962;17: 849 .

8 Romans A, ed. Applied statistic for science and industry. London: Allyn and Bacon, 1977.

9 Bartolo DCC, Read NW, Jarrett JA, Read MG, Donnelly TC, Johnson AG. Differences in anal sphincter function and clinical presentation in patients with idiopathic faecal incontinence. Gastroenterology 1983; 85: 68-75.

10 Henry MM, Parks AG, Swash M. The pelvic floor musculature in the descending perineum syndrome. Br F Surg 1982; 69: $470-2$.

11 Sun WM, Read NW, Donnelly TC. Anorectal function in incontinent patients with cerebrospinal disease. Gastroenterology 1990; 99: 1372-9.

12 Sun WM, Donnelly TC, Read NW. Impaired internal anal sphincter in a sub-group of patients with idiopathic faecal incontinence. Gastroenterologv 1989; 97: 130-5.

13 Snooks SJ, Swash M, Setchell M, Henry MM. Injury to innervation of pelvic floor sphincter musculature in childbirth. Lancet 1984; ii: 546-50.

14 Henry MM, Swash M. Faecal incontinence: pathogenesis and clinical features. In: Henry MM, Swash M, eds. Coloproctology and the pelvic floor: pathophwsiology and management. tology and the pelvic floor: pathophysiol

15 Snooks SJ, Swash M. Electromyography and nerve latency studies. In: Gooszen, et al eds. Disordered defaecation. Lancaster: Martinus Nijhoff, 1987: 17-30

16 Sun WM, Read NW. Occult spinal lesions: a common undetected cause of faecal incontinence. Lancet 1990; i: 166

7 Bartolo DCC, Jarratt JA, Read MG, Donnelly TC, Read NW The role of partial denervation of the puborectalis in idiopathic faecal incontinence. Br $\mathcal{F}$ Surg 1983; 70: 66+7.

18 Read NW, Bartolo DCC, Read MG. Differences in anal function in patients with incontinence to solids and in patients with incontinence to liquids. BrF Surg 1984; 71: 3942 .

19 Kiff ES, Swash M. Slowed conductions in the pudendal nerves in idiopathic (neurogenic) faecal incontinence. Br $\mathcal{F}$ Surg 1984; 71:614-6.

20 Schuster $M M$. The riddle of the sphincters. Gastroenterology 1975; 69: 249-62.

21 Parks AG. Anorectal incontinence. Proc $R$ Soc Med 1975; 68: 681-90.

22 Schuster MM. Motor activity of rectum and anal sphincter in continence and defaecation. In: Code CF, ed. Handbook of physiology. Vol 4. Section 6. Alimentary canal. Washington. DC: American Physiological Society, 1968: 2121-39.

23 Bouvier M, Gonella J. Nervous control of the internal anal sphincter of the cat. F Physiol (Lond) $1981 ; 310: 457-69$.

24 Burleigh DE, D'Mello A. Physiology and pharmacology of the internal anal sphincter. In: Henry MM, Swash M, eds. Coloproctology and the pelvic floor. Pathophysiology and management. London: Butterworths, 1985: 22-41.

25 Christensen J, Rich GA. The distribution of myelinated nerves in the ascending nerves and myenteric plexus of the cat colon. Am $\mathcal{F}$ Anat 1987; 178: 250-8

26 Whitehead WE, Engel BT, Schuster MM. Irritable bowel syndrome: physiological and psychological differences between diarrhoea predominant and constipation predominant patients. Dig Dis $S$ ci $1980 ; 25: 404-13$.

27 Prior A, Maxton DG, Whorwell PJ. Anorectal manometry in irritable bowel syndrome: differences between diarrhoea and constipation predominant subject. Gut 1990; 31: 458-62.

28 Ritchie J. Pain from distension of the pelvic colon by inflating a balloon in the irritable colon syndrome. Gut 1973; 14: 12532.

29 Sun WM, Read NW, Bannister JJ, Shorthouse AJ. A common pathophysiology for full thickness rectal prolapse, anterior mucosal prolapse and solitary rectal ulcer. $\operatorname{Br} \mathcal{F}$ Surg 1989; 76: $290-5$

30 Sun WM, Read NW, Miner PB, Kerrigan DD, Donnelly TC. The role of transient internal sphincter relaxation in faecal incontinence? Int 7 Colorect Dis 1990; 5: 31-6. 